\author{
Abstracta Iranica \\ Abstracta Iranica Revue bibliographique pour le domaine irano-aryen \\ Volume 37-38-39 | 2018 \\ Comptes rendus des publications de 2014-2016
}

\title{
Judith Pfeiffer (ed.). Politics, Patronage and the Transmission of Knowledge in 13th-15th Century Tabriz
}

Sandra Aube

\section{(2) OpenEdition}

Édition électronique

URL : http://journals.openedition.org/abstractairanica/42466

DOI : 10.4000/abstractairanica.42466

ISBN : 1961-960X

ISSN : 1961-960X

Éditeur :

CNRS (UMR 7528 Mondes iraniens et indiens), Éditions de l'IFRI

Référence électronique

Sandra Aube, « Judith Pfeiffer (ed.). Politics, Patronage and the Transmission of Knowledge in 13th-15th Century Tabriz », Abstracta Iranica [En ligne], Volume 37-38-39 | 2018, document 1, mis en ligne le 10 mars 2018, consulté le 28 septembre 2020. URL : http://journals.openedition.org/abstractairanica/ 42466 ; DOI : https://doi.org/10.4000/abstractairanica.42466

Ce document a été généré automatiquement le 28 septembre 2020

Tous droits réservés 


\title{
Judith Pfeiffer (ed.). Politics, Patronage and the Transmission of Knowledge in 13th-15th Century Tabriz
}

\author{
Sandra Aube
}

\section{RÉFÉRENCE}

Judith Pfeiffer (ed.). Politics, Patronage and the Transmission of Knowledge in 13th-15th

Century Tabriz. Leyde/Boston : Brill, Iran Studies, volume 8, 2014, 397 p., 34 illust. ISBN :

9789004255395

1 Entre les XIII e et $\mathrm{XV}^{\mathrm{e}}$ siècles, Tabriz a constitué un centre artistique, commercial et politique de premier plan; son histoire est pourtant restée par bien des aspects mal connue. Le présent volume, édité par Judith Pfeiffer, contribue à combler ces manques en proposant des perspectives croisées sur l'histoire de Tabriz, et plus spécifiquement sur sa vie intellectuelle au cours des XIII ${ }^{e}$ et XIV ${ }^{e}$ siècles. Ce recueil de treize articles fait suite à un workshop organisé au Research Center for Anatolian Civilization de la Köç University, à Istanbul, les $1^{\text {er }}$ et 2 octobre 2011.

2 Le livre s'organise en trois parties, les deux premières se focalisant plus spécifiquement sur la période il-khânide. La première partie, intitulée «Intellectuals, Bureaucrats and Politics », analyse les élites, et notamment leurs relations avec les sphères religieuses. Elle réunit les quatre contributions suivantes :

- Reuven Amitai, « Hülegü and His Wise Men: Topos or Reality?», p. 15-34,

4 - Devin DeWeese, «'Alā' al-Dawla Simnānī's Religious Encounters at the Mongol Court near Tabriz », p. 35-76,

5 - Domenico Ingenito, «'Tabrizis in Shiraz are Worth Less Than a Dog’: Sa'dī and Humān, a Lyrical Encounter », p. 77-127, 
6 - Judith Pfeiffer, «Confessional Ambiguity vs. Confessional Polarization: Politics and the Negotiation of Religious Boundaries in the Ilkhanate », p. 129-168.

7 La seconde partie - «The Transmission of Knowledge »- s'intéresse plus spécifiquement à certaines productions intellectuelles. Il débute avec deux importantes contributions sur le complexe de Rashîd al-din et sa production manuscrite, puis se poursuit avec deux études portant sur l'astronomie :

8 - Birgitt Hoffmann, «In Pursuit of Memoria and Salvation: Rashīd al-Dīn and His Rab'-i Rashīdī », p. 171-185 (3 ill.),

9 - Nourane Ben Azzouna, «Rashīd al-Dīn Faḍl Allāh al-Hamadhānī's Manuscript Production Project in Tabriz Reconsidered», p. 187-200,

10 - Robert Morrison, "What Was the Purpose of Astronomy in Ijjì's Kitāb al-Mawāqif fi 'ilm al-kalām? », p. 201-229,

11 - F. Jamil Ragep, « New Light on Shams », p. 231-247.

12 En examinant les réseaux commerciaux et artistiques entre les XIII ${ }^{\mathrm{e}}$ et $\mathrm{XV}^{\mathrm{e}}$ siècles, la troisième partie - «Tabriz and Interregional Networks»- ouvre enfin sur une chronologie plus étendue. Les deux premiers articles examinent successivement le rôle des communautés chrétiennes, puis des marchands européens, dans le développement commercial mais aussi intellectuel de Tabriz; les trois dernières contributions s'intéressent à la vie artistique de Tabriz :

13 - Johannes Preiser-Kapeller, «Civitas Thauris. The Significance of Tabriz in the Spatial Frameworks of Christian Merchants and Ecclesiastics in the $13^{\text {th }}$ and $14^{\text {th }}$ Centuries ", p. 251-299 (10 cartes).

14 - Patrick Wing, "'Rich and Goods and Abounding in Wealth': The Ilkhanid and PostIlkhanid Ruling Elite and the Politics of Commercial Life at Tabriz, 1250-1400 ", p. 300-320.

15 - 321-356 (15 ill.),

16 - Joachim Gierlichs, « Tabrizi Woodcarvings in Timurid Iran », p. 357-369 (6 ill.),

17 - Ertuğrul Ökten, «Imperial Aqquyunlu Construction of Religious Establishments in the Late Fifteenth Century Tabriz », p. 371-385.

18 En croisant les approches et les problématiques, ce recueil d'articles met en valeur l'effervescence intellectuelle de Tabriz aux XIII ${ }^{\mathrm{e}}$ et XIV ${ }^{\mathrm{e}}$ siècles, et les interactions entre les différentes institutions et groupes sociaux. L'ouvrage démontre combien ce dynamisme intellectuel se développe relativement indépendamment d'un patronage politique officiel. Le volume qu'édite Judith Pfeiffer constitue sans conteste un nouvel ouvrage de référence sur l'histoire de Tabriz. 


\section{AUTEURS}

\section{SANDRA AUBE}

CNRS, Mondes iranien et indien, Paris 